\title{
Gestión de contenidos digitales. Primera aplicación docente de CONTENTdm en la universidad española: estudios de Grado y Máster en la Facultad de Ciencias de la Documentación de la UCM
}

\author{
Mariana LÓPEZ HURTADO \\ Instituto Nacional de Administración Pública (INAP) \\ m.lopezhurtado@gmail.com \\ Francisco José VALENTÍN RUIZ \\ doc6 \\ vruiz@doc6.es \\ María OLIVERA ZALDUA \\ Departamento de Biblioteconomía y Documentación de la UCM \\ molivera@pdi.ucm.es
}

Recibido: Enero 2012

Aceptado: Julio 2012

Resumen: Cada vez se generan más documentos en formato digital por lo que se hace imprescindible la correcta gestión y difusión de los mismos. Entre los sistemas para el tratamiento de dichos contenidos digitales que mejor acogida han tenido en los últimos tiempos se encuentran los servicios en la nube. Como modelo se presenta en este artículo la primera experiencia docente en la universidad española con el programa de gestión CONTENTdm de OCLC, aplicado a la colección audiovisual de la Facultad de Ciencias de la Documentación de la UCM.

Palabras clave: CONTENTdm; Gestión de contenidos digitales; Colecciones digitales; Cloud computing; Aplicaciones docentes; OCLC; Universidad Complutense de Madrid.

Digital content management. First educational application of CONTENTdm at the university: Bachelor and Master Studies in the Faculty of Information Science of the UCM

\begin{abstract}
More and more documents are created in digital format, so it is essential the proper management and dissemination of them. The services in the cloud are among the systems for the processing of such digital content that have been better received in recent times. The first teaching experience in Spanish's university with the management software of OCLC, CONTENTdm, applied to the audiovisual collection of the Faculty of Information Science of the UCM is presented as a model in this article.
\end{abstract}


Keywords: CONTENTdm; Digital content management; Digital collections; Cloud computing; Educational applications; OCLC; Universidad Complutense de Madrid.

\section{INTRODUCCIÓN}

Inmersos en un mundo digital y en un contexto creciente de creación de contenidos en formatos electrónicos, tenemos pendiente el reto de la gestión, preservación y difusión en la Web, lo que permite que las colecciones de las grandes instituciones culturales o de las organizaciones con fines comerciales sean visibles. En el caso de las instituciones públicas, su papel de servidoras de la sociedad y de depositarias de la cultura exige la máxima visibilidad de los fondos que custodian; en el de los centros de documentación pertenecientes a organizaciones con fines comerciales, se debe justificar la existencia, y tanto la difusión de su actividad como la de los contenidos que generan es fundamental para lograrlo.

No es posible llevar a cabo la difusión sin una adecuada gestión que recoja los aspectos relacionados con la descripción del contenido, la administración de los derechos de uso y de propiedad intelectual asociados, las características de la visualización en la Web y la información necesaria para su preservación. Esta última cuestión aún no se contempla como una necesidad en las grandes instituciones culturales (entiéndase archivos históricos, bibliotecas, etc.) porque la mayoría de la documentación histórica que se conserva tiene un soporte impreso.

Existen diferentes soluciones en lo que se refiere a la gestión y difusión de contenidos digitales. Las más tradicionales son las aplicaciones comerciales entre las que podemos citar Adobe Bridge o Apple-Aperture. Más recientemente las herramientas de código abierto, como Darktable, están acaparando una parte importante del mercado debido a sus ventajas con respecto a las anteriores: precio inicial, aunque después hay que añadir los costes de instalación, adaptación y en algunos casos también de almacenamiento de las aplicaciones; o la posibilidad de que documentalistas participen del proceso de desarrollo. Sin embargo las aplicaciones comerciales tienen el respaldo del soporte técnico y los problemas que surgen con las herramientas de código abierto deben ser resueltos por los propios documentalistas aunque eventualmente haya empresas que puedan realizar este mantenimiento.

No obstante, en este trabajo queremos centrarnos en unas soluciones que están cobrando gran importancia, son las cloud computing, modelo basado en la oferta de servicios informáticos desde la Web. Es objeto demostrar la validez de estos sistemas cloud computing para la gestión de colecciones digitales, para lo cual se han realizado diversas prácticas docentes con alumnos de la Facultad de Ciencias de la Documentación de la Universidad Complutense de Madrid. No se pretende realizar un análisis comparativo entre sistemas, por lo que aunque se incluyan unos apuntes en este sentido la comparación será fruto de un estudio posterior.

Los servicios en la nube ofrecen ventajas frente a estos otros métodos -herramientas comerciales, software de código abierto- ya que, en algunos casos, permiten eliminar los 
costes de almacenamiento al estar incluidos en el servicio, o simplifican los procesos de modo que cualquier usuario es capaz de gestionar las aplicaciones de forma prácticamente autónoma y con un mínimo o nulo desarrollo informático. Además existen ahorros considerables en equipos informáticos gracias a la externalización de los servicios, y facilitan la colaboración entre distintas entidades al permitir el uso compartido de recursos sin desarrollos adicionales ${ }^{1}$.

También encontramos, inconvenientes como las cuestiones acerca de la seguridad de los datos almacenados en estas plataformas o la propiedad del conocimiento generado si el servicio desaparece o los clientes dejan de pagar las licencias ${ }^{2}$, y una serie de obstáculos de carácter informático al que se enfrentan este tipo de herramientas: dudas acerca de la posibilidad de migrar datos procedentes de un sistema cloud computing a otro distinto; o la imprevisibilidad del rendimiento de las plataformas ${ }^{3}$. Sin duda, las características de las herramientas en la nube exigen el desarrollo de requerimientos que garanticen cuestiones como la preservación digital, y así se planteó en la última conferencia del Consejo Internacional de Archivos (ICA) celebrada en Toledo en octubre de 2011 (tabla 1).

Tabla 1. Ventajas e inconvenientes de los servicios en la nube

\begin{tabular}{|c|c|}
\hline \multicolumn{2}{|c|}{ SERVICIOS EN LA NUBE } \\
\hline VENTAJAS & INCONVENIENTES \\
\hline Costes de almacenamiento & Seguridad de los datos \\
\hline Simplicidad de procesos & $\begin{array}{c}\text { Propiedad del conocimiento } \\
\text { generado }\end{array}$ \\
\hline Ahorro en equipos informáticos & Migración de datos \\
\hline Colaboración entre entidades & $\begin{array}{c}\text { Imprevisión del rendimiento de las } \\
\text { plataformas }\end{array}$ \\
\hline
\end{tabular}

Un modelo de tecnología cloud computing es CONTENTdm, gestor de contenidos digitales de todo tipo (imágenes, audios, videos, recursos web, documentos electrónicos, etc.) que al mismo tiempo permite difundir en la aplicación las colecciones descritas de forma prácticamente automática. En España

${ }^{1}$ URUEÑA, A. (coord.). Cloud Computing. Retos y Oportunidades. Madrid: Observatorio Nacional de las Telecomunicaciones y de la SI del Ministerio de Industria, Energía y Turismo, 2012, $341 \mathrm{p}$.

${ }^{2}$ LARA-NAVARRA, P.; MANIEGA-LEGARDA, D. "Conocimiento en la nube: evolución de las intranets”. El Profesional de la Información, 2011, v. 20, n. 2, pp.175-181.

${ }^{3}$ ARMBRUST, M... et al. Above the Clouds: A Berkeley View of Cloud Computing. Berkeley: University of California, 2009. Disponible en

"http://www.eecs.berkeley.edu/Pubs/TechRpts/2009/EECS-2009-28.pdf" [Consulta: 16 julio 2012]. 
cuenta con ejemplos de aplicación en: Instituto Cervantes ${ }^{4}$, Consorci de Biblioteques Universitàries de Catalunya o Institut Cartogràfic de Catalunya ${ }^{5}$.

CONTENTdm es una herramienta fácilmente adaptable a las diferentes necesidades de los centros de documentación debido a que permite combinar tanto la gestión de grandes volúmenes de contenidos digitales como proporcionar un enfoque documental, del que carecen muchos de los programascitados anteriormente. Además, proporciona unos sistemas de búsqueda basados en herramientas de descubrimiento, un concepto acuñado recientemente y que tiene por objeto asistir al usuario en la tarea de búsqueda proporcionando sugerencias, filtros con los que refinar los resultados, etc.

Entre los aspectos a mejorar de se encuentra la necesidad de depurar las traducciones a otros idiomas distintos del inglés de los interfaces, la imposibilidad de incorporar ciertas funcionalidades del tratamiento de contenidos digitales sin la instalación de un programa adicional en entorno local, denominado ProjectClient, por ejemplo: carga de contenidos en bloque, edición de imágenes o incorporación de marcas de agua. A esto hay que sumar las limitaciones actuales para hacer el sistema interoperable con estándares de metadatos más allá de Dublin Core y del protocolo OAI-PMH, aunque esto de por sí sea todo un avance en comparación con otros sistemas que no permiten ningún tipo de interoperabilidad.

En definitiva, la gestión, difusión y preservación de contenidos digitales son temas que se están tratando en el ámbito profesional de la Biblioteconomía y Documentación. En este trabajo mostramos cómo a partir de CONTENTdm se han abordado, principalmente, las cuestiones de gestión y difusión de contenidos digitales por estudiantes universitarios. La razón de emplear este servicio deriva, como se verá, del acuerdo suscrito entre la Facultad de Ciencias de la Documentación y OCLC:

En este contexto exponemos los resultados de la primera experiencia universitaria en España en gestión de contenidos digitales con esta aplicación, realizada mediante sesiones monográficas con la colección audiovisual de la Facultad de Ciencias de la Documentación. En este propósito han participado cerca de un centenar de estudiantes para los que se han creado cuentas en OCLC, incorporadas al módulo de administración de CONTENTdm junto con la gestión de los permisos correspondientes.

${ }^{4}$ IGLESIA SÁNCHEZ, Y.; UGUINA COCOSTEGÜE, P.; FUERTES CONDE, J. M. "Adaptación del gestor de colecciones digitales CONTENTdm en un entorno corporativo". El Profesional de la Información, 2011, v. 20, n. 6, pp. 689-693.

${ }_{5}^{5}$ ROSET, R.; REOLLO TUDÓ, S.; TORRE MARÍN, R. "Gestión de objetos digitales con CONTENTdm: estudio de caso en el Consorci de Biblioteques Universitàries de Catalunya y el Institut Cartogràfic de Catalunya". El Profesional de la Información, 2012, v. 21, n. 1, pp. 91-97. 


\section{APLICACIÓN DOCENTE DE CONTENTDM EN LA FACULTAD DE CIENCIAS DE LA DOCUMENTACIÓN}

La hipótesis planteada fue la aplicación de los sistemas de gestión CONTENTDdm a un conjunto documental en el aula, desarrollando la práctica y analizando los resultados. Para ello el 27 de julio de 2011 se firmó el primer acuerdo en España entre OCLC y una institución universitaria: la Facultad de Ciencias de la Documentación de la UCM. Esta colaboración permite a OCLC difundir el gestor entre futuros profesionales en Biblioteconomía y Documentación, facilitando el acceso a una aplicación puntera en la gestión de contenidos, muy extendida en universidades e instituciones culturales norteamericanas.

En octubre de 2011 OCLC proporcionó a la Facultad de Ciencias de la Documentación una cuenta para utilizar la versión 6.1 del programa, que incluía un portal (http://cdm15832.contentdm.oclc.org) y un almacenamiento remoto limitado por el número de registros y por el tamaño de los mismos, pero que servía perfectamente a los objetivos docentes para los que se había planteado el acuerdo. A partir de ese momento se inició un proceso de análisis de las funcionalidades de la aplicación, de sus posibilidades de adaptación y de valoración de la viabilidad para que los estudiantes realizaran prácticas.

\section{METODOLOGÍA}

Una vez realizado el estudio inicial se diseñó un plan de prácticas en torno a CONTENTdm para los alumnos de las asignaturas Documentación Iconográfica, Documentación Fotográfica y Audiovisual, y Documentación Multimedia, en los estudios de Grado en Información y Documentación y Máster Oficial en Gestión de la Documentación.

La asignatura Documentación Fotográfica y Audiovisual se imparte en los estudios de Grado, es optativa en los cursos $3^{\circ}$ y $4^{\circ}$, con una fuerte demanda que en el curso 2011-2012 ha alcanzado un centenar de alumnos en los grupos de mañana y tarde. Las otras dos se imparten en el Máster en la especialidad de Medios de Comunicación. Las tres asignaturas tienen en sus programas lecciones específicas dedicadas a la gestión de contenidos, uno de los aspectos clave.

Los responsables de estas asignaturas Juan Miguel Sánchez Vigil y María Olivera Zaldua, con el apoyo del Departamento de Biblioteconomía y Documentación y de la Facultad de Ciencias de la Documentación acogieron con entusiasmo la propuesta de doc6 (distribuidor de los productos de OCLC en España) para suscribir el acuerdo que ha permitido utilizar CONTENTdm. OCLC facilitó la infraestructura técnica necesaria, y adecuaron la apariencia y funcionalidades a las necesidades educativas Francisco José Valentín Ruiz y 
Mariana López Hurtado. Los profesores asumieron los aspectos docentes y formales.

El método de trabajo se inició con la adaptación del portal que OCLC había proporcionado a la Facultad de Ciencias de la Documentación, a partir de una «Colección audiovisual» (materiales generados y cedidos por los profesores como ejemplo para los estudiantes). El proceso de adaptación resultó extremadamente sencillo puesto que la plataforma es intuitiva y de fácil manejo. Se diseñó una cabecera institucional, se reorganizó la presentación de los contenidos, las opciones de búsqueda, los textos explicativos que debían aparecer, las direcciones de contacto, el idioma y las condiciones de acceso de los usuarios (figura 1).

Figura 1. Página principal de la colección audiovisual de la Facultad de Ciencias de la Documentación de la $\mathrm{UCM}$

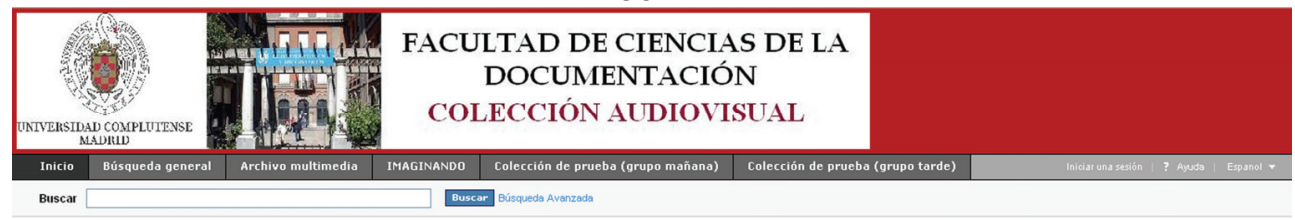

Colección audiovisual de la Facultad de Ciencias de la Documentación (UCM)

Todas las colecciones
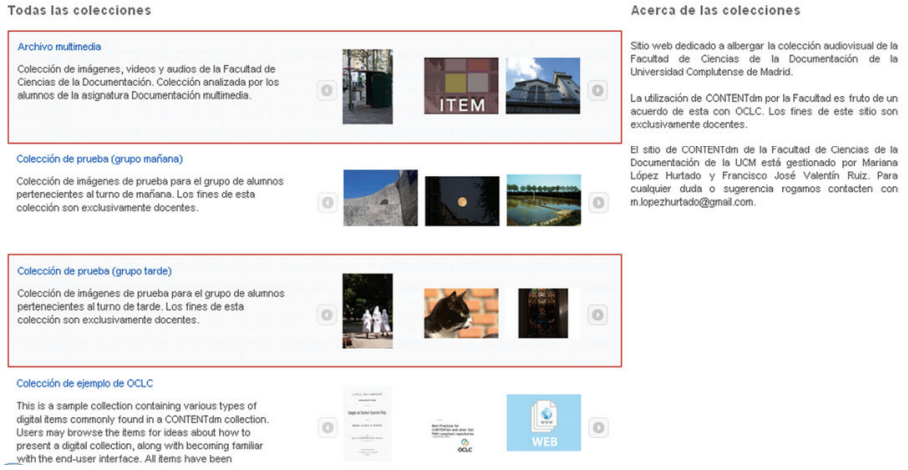

Tras la adaptación del portal web y el estudio de las opciones de administración, se prepararon tres sesiones monográficas para cada una de las asignaturas citadas. Las sesiones se idearon para que los alumnos describieran una serie de documentos, elaborando dos plantillas de campos, una para las asignaturas Documentación Iconográfica y Documentación Fotográfica y Audiovisual (tabla 2), y la otra para la asignatura Documentación Multimedia (tabla 3). Para la elaboración de dichas plantillas se ha seguido un modelo de análisis documental basado en tres puntos de vista: identificación general, con los datos que son imprescindibles para la identificación de los documentos; características técnicas 
de los propios documentos; y descripción de contenidos ${ }^{6}$. Los campos finalmente utilizados están basados en el esquema propuesto por el profesor Félix del Valle ${ }^{7}$.

CONTENTdm permite utilizar la estructura de Dublin Core para la definición de los campos descriptivos, así como incorporar otros para la introducción de metadatos de preservación o de gestión de derechos. Debido al reducido tiempo de las sesiones se optó por crear una estructura con aquellos campos básicos para la descripción del contenido, y otros técnicos propios de las imágenes extraídos de las etiquetas IPTC. Estos últimos se añadieron simplemente para mostrar las posibilidades de la plataforma.

A continuación se crearon una serie de vocabularios controlados para normalizar la descripción de los campos y, finalmente, se definieron las características de las colecciones para su visualización en la Web. Participaron un total de 85 alumnos, y se trataron 367 documentos, con una metodología y un resultado que se valoran a continuación. Por último se procedió a la catalogación de la colección, distribuyendo los descriptores en cronológicos, geográficos, onomásticos y temáticos, y a la obtención de resultados.

Tabla 2. Plantilla de campos diseñada para las asignaturas Documentación Fotográfica y Audiovisual, y Documentación Iconográfica

Documentación Fotográfica y Audiovisual Documentación Iconográfica

\begin{tabular}{|l|l|l|l|l|l|}
\hline $\begin{array}{c}\text { Nombre del } \\
\text { campo }\end{array}$ & $\begin{array}{l}\text { Correspondencia } \\
\text { con Dublin Core }\end{array}$ & Tipo de datos & $\begin{array}{c}\text { Nombre del } \\
\text { campo }\end{array}$ & $\begin{array}{l}\text { Correspondencia } \\
\text { con Dublin Core }\end{array}$ & Tipo de datos \\
\hline Título & Título & Texto & Derechos & Derechos & Texto \\
\hline Fecha & Cobertura & Texto & Notas & Ninguno & Texto \\
\hline $\begin{array}{l}\text { Fecha de } \\
\text { captura }\end{array}$ & Fecha & Fecha & Notas internas & Ninguno & Texto \\
\hline Descripción & Descripción & Texto & Transcripción & Ninguno & Texto \\
\hline $\begin{array}{l}\text { Descriptores } \\
\text { temáticos }\end{array}$ & Materia & Texto & $\begin{array}{l}\text { Fabricante de la } \\
\text { cámara }\end{array}$ & Ninguno & Texto \\
\hline $\begin{array}{l}\text { Descriptores } \\
\text { onomásticos }\end{array}$ & Materia & Texto & $\begin{array}{l}\text { Modelo de la } \\
\text { cámara }\end{array}$ & Ninguno & Texto \\
\hline $\begin{array}{l}\text { Descriptores } \\
\text { geográficos }\end{array}$ & Cobertura & Texto & Punto F & Ninguno & Texto \\
\hline Autor & Autor & Texto & $\begin{array}{l}\text { Tiempo de } \\
\text { exposición }\end{array}$ & Ninguno & Texto \\
\hline Editor & Editor & Texto & Velocidad ISO & Ninguno & Texto \\
\hline
\end{tabular}

${ }^{6}$ SÁNCHEZ VIGIL, J. M. El documento fotográfico: historia, usos y aplicaciones. Gijón: Trea, 2006, p. 175.

7 VAlLE GASTAMinZA, F. (ed.). Manual de documentación fotográfica. Madrid: Síntesis, 1999. 


\begin{tabular}{|l|l|l|l|l|l|} 
Tipo & Tipo & Texto & $\begin{array}{l}\text { Compensación } \\
\text { de exposición }\end{array}$ & Ninguno & Texto \\
\hline Formato & Formato & Texto & Distancia focal & Ninguno & Texto \\
\hline Resolución & Ninguno & Texto & $\begin{array}{l}\text { Apertura } \\
\text { máxima }\end{array}$ & Ninguno & Texto \\
\hline Tamaño & Ninguno & Texto & $\begin{array}{l}\text { Modo de } \\
\text { medición }\end{array}$ & Ninguno & Texto \\
\hline Catalogador & Ninguno & Texto & $\begin{array}{l}\text { Distancia al } \\
\text { objeto }\end{array}$ & Ninguno & Texto \\
\hline Identificador & Identificador & Texto & Modo de flash & Ninguno & Texto \\
\hline Fuente & Fuente & Texto & $\begin{array}{l}\text { Intensidad de } \\
\text { flash }\end{array}$ & Ninguno & Texto \\
\hline Idioma & Idioma & Texto & & &
\end{tabular}

Tabla 3. Plantilla de campos diseñada para la asignatura Documentación Multimedia

\begin{tabular}{|c|c|c|}
\hline \multicolumn{3}{|c|}{ Documentación Multimedia } \\
\hline Nombre del campo & $\begin{array}{l}\text { Correspondencia } \\
\text { con Dublin Core }\end{array}$ & $\begin{array}{c}\text { Tipo de } \\
\text { datos }\end{array}$ \\
\hline Título & Título & Texto \\
\hline Autor & Autor & Texto \\
\hline Fecha de creación & Fecha & Texto \\
\hline Resumen & Descripción & Texto \\
\hline $\begin{array}{l}\text { Descriptores onomásticos (personas } \\
\text { físicas y jurídicas) }\end{array}$ & Materia & Texto \\
\hline $\begin{array}{l}\text { Descriptores geográficos (lugares, } \\
\text { accidentes geográficos) }\end{array}$ & Cobertura & Texto \\
\hline $\begin{array}{l}\text { Descriptores cronológicos (día, mes, } \\
\text { año, siglo) }\end{array}$ & Materia & Texto \\
\hline $\begin{array}{l}\text { Descriptores temáticos (materias y } \\
\text { temas) }\end{array}$ & Materia & Texto \\
\hline Pie de foto informativo & Ninguno & Texto \\
\hline Duración & Ninguno & Texto \\
\hline Derechos & Derechos & Texto \\
\hline Documento & Tipo & Texto \\
\hline Catalogador & Ninguno & Texto \\
\hline
\end{tabular}




\section{DESARROLLO Y RESULTADOS}

Una vez diseñados los aspectos explicados anteriormente se realizaron tres lecciones estructuradas del siguiente modo:

- Exposición de los fundamentos de las plataformas cloud computing.

- Introducción a CONTENTdm como aplicación en la nube para la difusión de contenidos digitales.

- Descripción de funcionalidades del sitio web y del módulo de administración.

- Explicación en detalle de la práctica a realizar por los estudiantes.

En las dos primeras sesiones monográficas se trabajó con imágenes digitales como tipología documental única por las características de las asignaturas. La tarea se basó en la catalogación de un conjunto de imágenes por parte de los alumnos siguiendo la plantilla. Previamente y durante el transcurso de esta práctica se simulaba un entorno colaborativo en el que se discutían las pautas más adecuadas para completar los campos.

La tercera sesión se realizó con contenidos audiovisuales, con la dificultad añadida de que para que los audios y videos se visualizaran embebidos en la web de la «Colección audiovisual», tuvieron que ser convertidos a formatos específicos (WAV o MP3 para audios y AVI o MPEG para los videos).

Una vez completadas todas las descripciones de los documentos se pasó a aprobar los registros. CONTENTdm permite establecer una revisión previa de los registros catalogados antes de su publicación en la Web. Gracias a esta funcionalidad se mostró a los estudiantes una posible organización real del trabajo en un centro de documentación, en el que los catalogadores se encargan de describir los contenidos digitales y en una fase posterior un responsable revisa los contenidos introducidos, valida las materias propuestas e indexa la colección (figura 2). 
Figura 2. Detalle de una de las imágenes incorporada a la colección y de su descripción siguiendo la plantilla diseñada

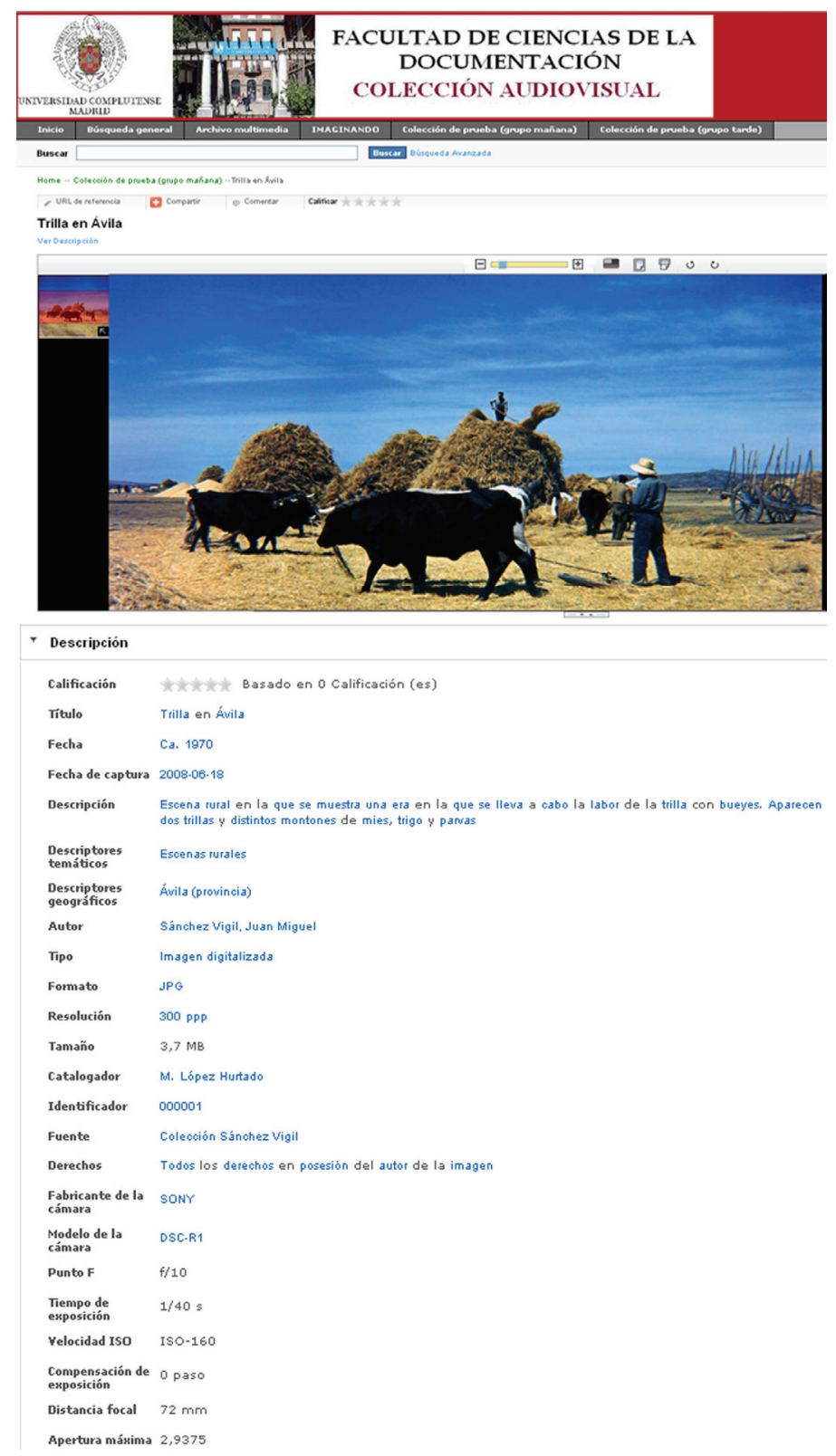


Figura 3. Revisión de los registros catalogados para su aprobación y posterior publicación en la Web

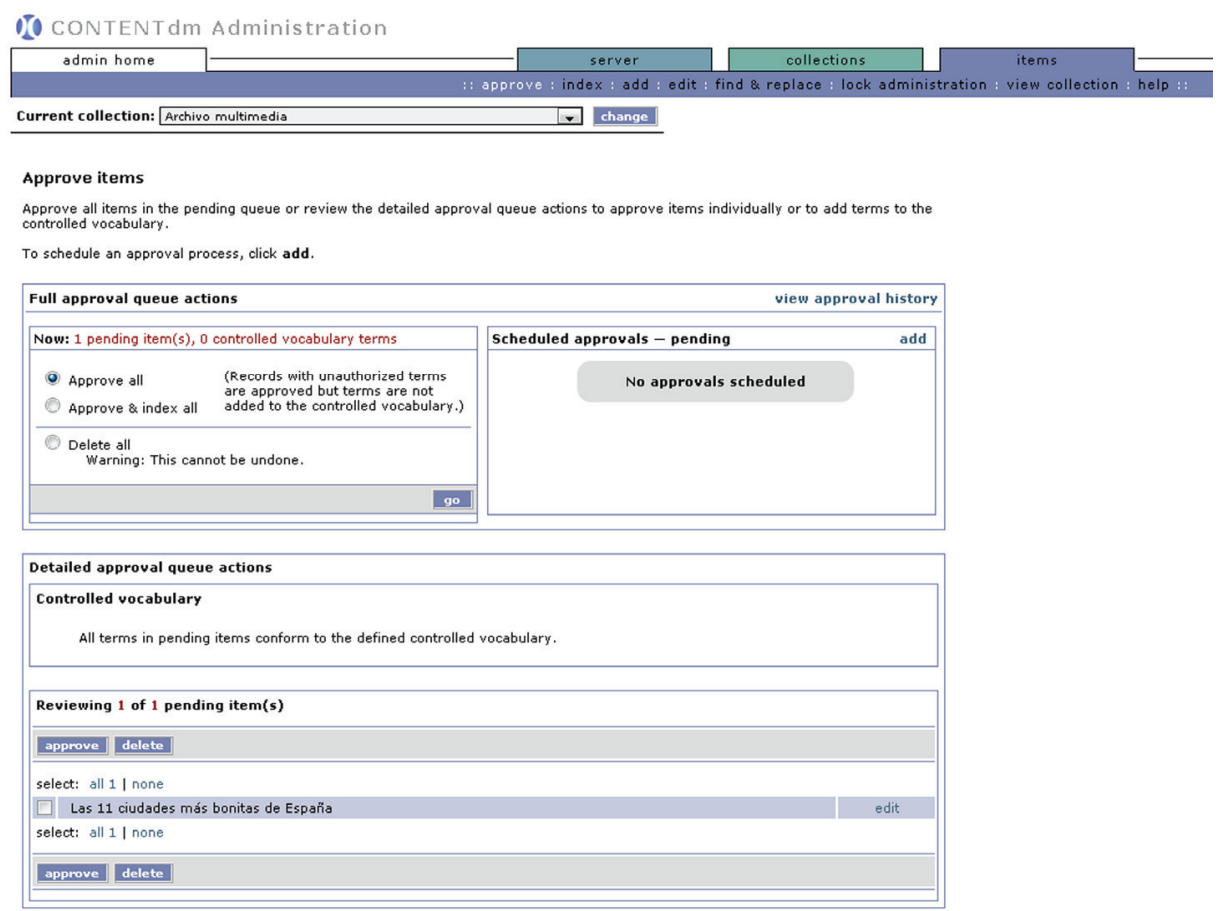

La última parte se destinó a la explicación de funciones adicionales, y entre ellas la creación de objetos compuestos, definidos como conjunto de contenidos digitales que guardan una relación entre sí (puede tratarse de las páginas de un libro o de una serie de imágenes con un tema en común). Se dio a conocer la posibilidad de realizar cambios y modificaciones en bloque, así como la exportación del contenido de las descripciones en formato XML conservando la estructura Dublin Core preestablecida. Otro de los aspectos de importancia en la gestión de imágenes, sobre todo en los centros de documentación con fines comerciales, es la posibilidad de que la visualización o la descarga se realice en baja resolución, sin intervención del documentalista, de forma que el propio sistema, en función de lo indicado en el módulo de administración, realiza la conversión.

Finalmente se permitió a los estudiantes que continuaran incluyendo contenidos durante un mes para que practicaran aportando nuevos contenidos a las colecciones (figura 3 ) y conocieran en profundidad la aplicación. Este proceso fue supervisado en todo momento desde el módulo de administración. 
Figura 4. Colección resultante de la práctica realizada en una de las sesiones monográficas

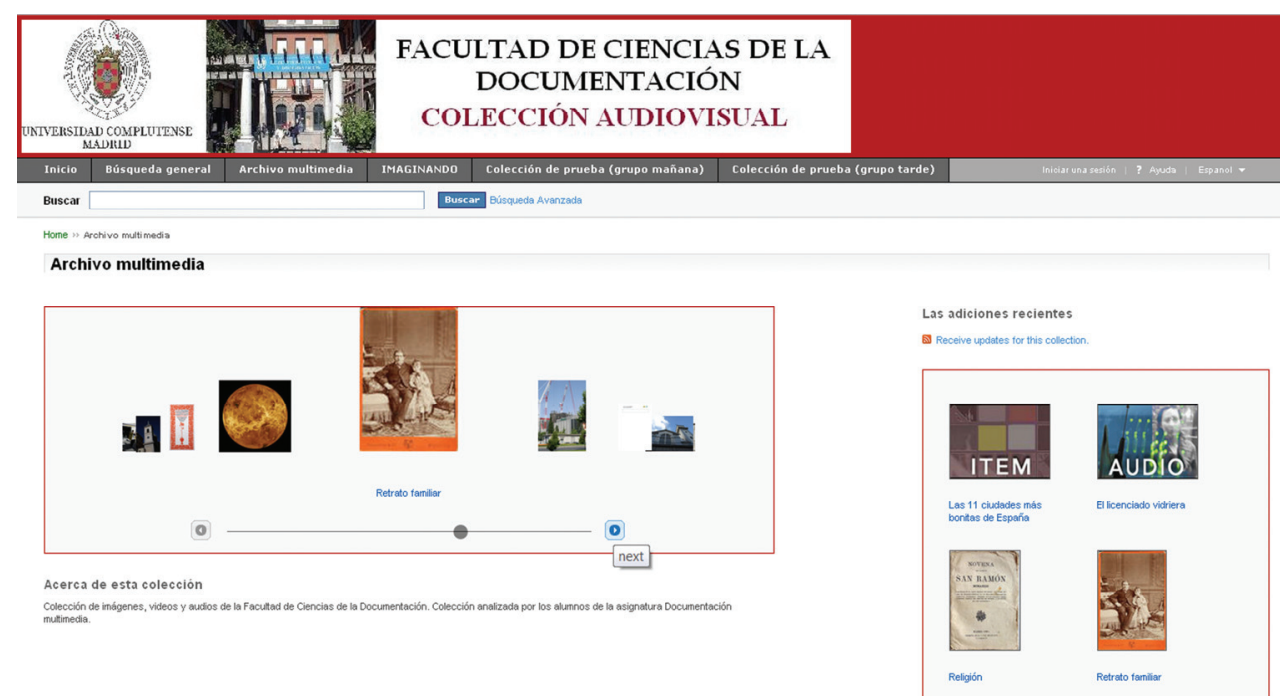

El resultado final es accesible desde el portal «Colección audiovisual de la Facultad de Ciencias de la Documentación» con un interfaz diseñado por Mariana López Hurtado y Francisco José Valentín Ruiz (http://cdm15832.contentdm.oclc.org). Como se ha citado con anterioridad, en la aplicación se han descrito un total de 367 documentos de temática y formatos diversos cuyos datos cuantitativos se ofrecen a continuación.

Cada estudiante describió una media de cuatro documentos (tabla 4), cumplimentando 13 campos en el caso de la asignatura de Documentación Multimedia y 33 para Documentación Iconográfica y Documentación Fotográfica y Audiovisual. En total se completaron 11.431 entradas (33 campos de las 333 imágenes de las dos primeras sesiones y 13 de cada uno de los 34 documentos de la tercera sesión).

Tabla 4. Número de documentos catalogados por asignaturas y estudiante

\begin{tabular}{|l|c|c|c|}
\hline \multicolumn{1}{|c|}{ Asignatura } & Estudiantes & Documentos & Media \\
\hline $\begin{array}{l}\text { Documentación Fotográfica y } \\
\text { Audiovisual }\end{array}$ & 42 & 179 & $4,26 \%$ \\
\hline Documentación Iconográfica & 31 & 154 & $4,96 \%$ \\
\hline Documentación Multimedia & 10 & 34 & $3,40 \%$ \\
\hline Total & 83 & 367 & $4,42 \%$ \\
\hline
\end{tabular}


Finalmente se validaron un total de 319 descriptores en una media de cuatro entradas por cada documento, resultando un valor aproximado de 1.300 entradas en los campos de materias (tabla 5). La mayoría fueron temáticos, sumando el $63,94 \%$ del total, seguido de los onomásticos con el 19,44\%, los geográficos con el $9,72 \%$ y por último los cronológicos con el $6,90 \%$.

Tabla 5. Distribución de descriptores según su tipología

\begin{tabular}{|l|c|c|}
\hline \multicolumn{3}{|c|}{ Descriptores } \\
\hline Tipología & Número & $\begin{array}{c}\% \text { sobre el } \\
\text { total }\end{array}$ \\
\hline Cronológicos & 22 & $6,90 \%$ \\
\hline Geográficos & 31 & $9,70 \%$ \\
\hline Onomásticos & 62 & $14,40 \%$ \\
\hline Temáticos & 204 & $63,90 \%$ \\
\hline \multicolumn{1}{|c|}{ Total } & 319 & $100 \%$ \\
\hline
\end{tabular}

La tipología documental estudiada fue la siguiente: fotografías, videos, audios, documentos pdf y recursos electrónicos, (tabla 6). Los tres grupos de trabajo analizaron fotografías, y solo el de Documentación Multimedia gestionó el resto de materiales. Prácticamente todos los documentos fueron fotografías (347), solo se catalogaron una veintena de videos y otros recursos electrónicos.

Tabla 6. Documentos descritos en las diferentes asignaturas por tipología

\begin{tabular}{|l|c|c|c|c|c|}
\hline \multicolumn{1}{|c|}{ Asignatura } & Fotografías & Videos & Audios & $\begin{array}{c}\text { Documentos pdf y } \\
\text { recursos electrónicos }\end{array}$ & Total \\
\hline $\begin{array}{l}\text { Documentación Fotográfica y } \\
\text { Audiovisual }\end{array}$ & 179 & - & - & - & 179 \\
\hline Documentación Iconográfica & 154 & - & - & - & 154 \\
\hline Documentación Multimedia & 14 & 6 & 6 & 8 & 34 \\
\hline Total & 347 & 6 & 6 & 8 & 367 \\
\hline
\end{tabular}

\section{CONCLUSIONES}

Determinamos que los sistemas en la nube y, más concretamente, CONTENTdm son servicios que permiten la gestión completa de contenidos digitales entendiendo como tal el almacenamiento de los contenidos, su análisis documental en función de los requisitos establecidos por el centro de documentación, la posibilidad de intercambio de información y la capacidad de generar ficheros de metadatos asociados a los contenidos y, lo que no es menos importante, su difusión en la Web de una manera inmediata. 
La preparación y realización de estas sesiones ha sido un reto por la novedad de la herramienta y por tratarse del primer acuerdo de este tipo en España entre OCLC y una institución universitaria. Por consiguiente, siguiendo los objetivos se ha realizado la primera experiencia universitaria en España con la aplicación CONTENTdm para la gestión de contenidos digitales, mediante sesiones monográficas que han permitido analizar documentalmente parte del material gráfico que conserva la Facultad de Ciencias de la Documentación.

Las prácticas realizadas responden a los objetivos del Espacio Europeo de Educación Superior, lo que ha permitido a los estudiantes participar de forma activa en sesiones con aplicación real de los conocimientos que adquieren en sus estudios, y al mismo tiempo obtener una formación para su inserción en el mercado laboral.

La generalización de las herramientas cloud computing obliga a replantear la inclusión de estas aplicaciones dentro de los planes de estudio de Biblioteconomía y Documentación. Además se hace imprescindible trasladar al ámbito universitario, para su estudio, los retos de la gestión, difusión y preservación de contenidos digitales, concretamente a los futuros profesionales de la Información, Biblioteconomía y Documentación.

Los resultados han sido plenamente satisfactorios, tanto por la participación de los estudiantes, como por la catalogación de los documentos utilizando herramientas cloud computing que, a pesar de los inconvenientes asociados, proporcionan una solución alternativa a la gestión de contenidos digitales.

\section{REFERENCIAS BIBLIOGRÁFICAS}

ARMBRUST, M... et al. Above the Clouds: A Berkeley View of Cloud Computing. Berkeley: University of California, 2009. Disponible en "http://www.eecs.berkeley.edu/Pubs/TechRpts/2009/EECS-2009-28.pdf" [Consulta: 16 julio 2012].

CONTENTdm Online help- Version 6. Manual de uso. Disponible en "http://contentdm.org/help6/collection-admin/index.asp" [Consulta: 15 marzo 2012].

CONTENTdm Overview [OCLC - CONTENTdm]. Disponible en

"http://www.oclc.org/contentdm/overview/default.htm" [Consulta: 15 marzo 2012].

IGLESIA SÁNCHEZ, Y.; UGUINA COCOSTEGÜE, P.; FUERTES CONDE, J. M. "Adaptación del gestor de colecciones digitales CONTENTdm en un entorno corporativo". El Profesional de la Información, 2011, v. 20, n. 6, pp. 689-693.

LARA-NAVARRA, P.; MANIEGA-LEGARDA, D. "Conocimiento en la nube: evolución de las intranets". El Profesional de la Información, 2011, v. 20, n. 2, pp.175-181. 
ROSET, R.; REOLLO TUDÓ, S.; TORRE MARÍN, R. "Gestión de objetos digitales con CONTENTdm: estudio de caso en el Consorci de Biblioteques Universitàries de Catalunya y el Institut Cartogràfic de Catalunya". El Profesional de la Información, 2012, v. 21, n. 1, pp. 91-97.

SÁNCHEZ VIGIL, Juan Miguel. El documento fotográfico. Gijón: Trea, pp.212-216.

URUEÑA, A. (coord.). Cloud Computing. Retos y Oportunidades. Madrid: Observatorio Nacional de las Telecomunicaciones y de la SI del Ministerio de Industria, Energía y Turismo, 2012, 341 p. 